\title{
PENGARUH PERENCANAAN KEBUTUHAN BAHAN BAKU DAN PENGAWASAN MUTU BAHAN BAKU TERHADAP KELANCARAN PROSES PRODUKSI PADA INDUSTRI OTOMOTIF
}

\author{
Ari Soeti Yani \\ Universitas 17 Agustus 1945 Jakarta \\ arisoetiyani@gmail.com \\ arisoetiyani@yahoo.co.id
}

\begin{abstract}
The purpose of this study is to determine the effect of raw material requirements planning and the empirical study of raw materials quality control towards the success of production process at PT. Inkoasku in North Jakarta. The company has been established since 1974 or had been around for 40 years. The sample that will be studied in this paper is derived from the monthly report data from PT. Inkoasku in North Jakarta from the period of January 2013 to December 2015. This study analyzes the relationship between effect of raw material requirements planning and the empirical study of raw materials quality control towards production process at PT. Inkoasku in North Jakarta. Statistic method used in this study is the multiple linear regression to first test the classical assumption. The results indicate that the raw material requirements planning has a partially positive influence towards the smoothness of the production process at PT. Inkoasku in North Jakarta. The raw materials quality control has a partially negative influence towards the smoothness of production process at PT. Inkoasku in North Jakarta.
\end{abstract}

Keywords: Raw Materials Requirement Planning, Raw Materials Quality Control, Production Process.

ABSTRAK
Tujuan penelitian ini untuk mengetahui pengaruh perencanaan kebutuhan bahan baku dan pengawasan mutu bahan baku secara empiris terhadap kelancaran proses produksi pada PT. Inkoasku di Jakarta Utara. Adapun perusahaan telah berdiri dari tahun 1974 atau sudah ada selama 40 tahun, sampel yang akan diteliti dalam penulisan skripsi ini adalah data laporan bulanan yang ada di PT. Inkoasku di Jakarta Utara periode Januari 2013-Desember 2015. Penelitian ini menganalisis hubungan antara pengaruh perencanaan kebutuhan bahan baku dan pengawasan mutu bahan baku secara empiris terhadap kelancaran proses produksi pada PT. Inkoasku di Jakarta Utara. Metode statistik yang digunakan adalah regresi linear berganda dengan melakukan uji asumsi klasik terlebih dahulu. Hasil penelitian ini menunjukan bahwa secara parsial perencanaan kebutuhan bahan baku memiliki pengaruh positif terhadap kelancaran proses produksi pada PT. Inkoasku di Jakarta Utara, dan secara parsial pengawasan mutu bahan baku memiliki pengaruh negatif terhadap kelancaran proses produksi pada PT. Inkoasku di Jakarta Utara.

Kata Kunci: Perencanaan Kebutuhan Bahan Baku, Pengawasan Mutu Bahan Baku, Kelancaran Proses Produksi 


\section{PENDAHULUAN}

Perusahaan manufaktur merupakan penopang utama perkembangan industri di sebuah negara. Perkembangan industri otomotif di sebuah negara juga dapat digunakan untuk melihat perkembangan industri secara nasional di negara tersebut. Perkembangan ini dapat dilihat baik secara aspek kualitas produk yang dihasilkannya maupun kinerja industri secara keseluruhan.

Salah satu faktor penunjang keberhasilan suatu industri otomotif ditentukan oleh kelancaran proses produksi. Sehingga bila proses produksi lancar, akan menghasilkan produk berkualitas, waktu penyelesaian pembuatan yang tepat dan ongkos produksi yang murah. Proses tersebut tergantung dari kondisi sumber daya yang dimiliki seperti manusia, mesin ataupun sarana penunjang lainnya, dimana kondisi yang dimaksud adalah kondisi siap pakai untuk menjalankan operasi produksinya, baik ketelitian, kemampuan ataupun kapasitasnya.

Dari survei pendahuluan penulis melihat bahwa PT. Inkoasku beberapa periode mengalami gangguan kelancaran proses produksi. Hal ini dapat dilihat dari data produksi sebagai berikut

Tabel 1 Data Produksi dan Data Target Produksi Tahun 2013 - 2015

\begin{tabular}{|c|c|c|c|c|}
\hline Tahun & $\begin{array}{c}\text { Target } \\
\text { (unit) }\end{array}$ & $\begin{array}{c}\text { produksi } \\
\text { (unit) }\end{array}$ & Selisih & $\begin{array}{c}\text { Persentase } \\
(\%)\end{array}$ \\
\hline 2013 & 2400000 & 2167238 & 232762 & $10 \%$ \\
\hline 2014 & 2400000 & 2104111 & 295889 & $13 \%$ \\
\hline 2015 & 2450000 & 2209628 & 240372 & $10 \%$ \\
\hline
\end{tabular}

Sumber : PT. Inkoasku, Jakarta

Dari pengamatan terlihat bahwa pengawasan mutu bahan baku masih perencanaan kebutuhan bahan baku dan terlihat lemah

Tabel 2 Data Kebutuhan Customer dan Produksi Bulan Januari 2013 - Maret 2015

\begin{tabular}{|c|c|c|}
\hline Bulan & $\begin{array}{c}\text { Kebutuhan Customer } \\
\text { (Unit) }\end{array}$ & $\begin{array}{c}\text { Produksi } \\
\text { (Unit) }\end{array}$ \\
\hline Jan'13 & 205600 & 186287 \\
\hline Feb'13 & 182700 & 192125 \\
\hline Mar'13 & 195600 & 176221 \\
\hline
\end{tabular}

Sumber : PT. Inkoasku, Jakarta.

Berdasarkan data diatas, maka penulis tertarik untuk melakukan penelitian tentang: "Pengaruh Perencanaan Kebutuhan Bahan Baku Dan Pengawasan Mutu Bahan Baku Terhadap Kelancaran Proses Produksi Pada Industri Otomotif Di Jakarta.
TINJAUAN PUSTAKA Perencanaan Kebutuhan Bahan Baku dengan Kelancaran Proses Produksi

Perencanaan kebutuhan bahan baku (Rangkaeti, 2007) adalah suatu sistem perencanaan dan penjadwalan kebutuhan material untuk produksi yang memerlukan beberapa tahap proses / fase, dari penelitian terdahulu yang dilakukan oleh : (1). Yuningsih (2010) 
dengan judul "Pengaruh Pengendalian Persediaan Bahan Baku Terhadap Kelancaran Proses Produksi”. Hal ini dikarenakan bahan baku merupakan unsur produksi yang sangat penting. Selain itu persediaan bahan baku tidak boleh berlebih dan berkurang. Karena, dengan persediaan bahan baku yang berlebih menimbulkan biaya produksi yang besar sehingga mengurangi laba perusahaan dan sebaliknya persediaan bahan baku yang kurang akan menghambat proses produksi. (2). Penelitian Hasanah (2008) dengan judul "Pengendalian Persediaan Bahan Baku Terhadap Kelancaran Proses Produksi Kertas Wood Free (WF)", memberikan temuan bahwa terdapat pengaruh yang positif dan kuat antara pengendalian bahan baku terhadap kelancaran proses produksi kertas wood free. Selanjutnya penelitian yang dilakukan oleh (3). Huda (2004) dengan judul "Analisis Persediaan Bahan Baku Kertas Dalam Mendukung Kelancaran Proses Produksi Buku Pada PT. Balai Pustaka (Persero) Jakarta", memberikan temuan bahwa jumlah persediaan yang ekonomis dengan menggunakan metode EOQ ternyata lebih murah dibandingkan dengan menggunakan metode yang dilakukan oleh perusahaan. Penelitian Mutiara (2010) dengan judul "Analisis Pengaruh Bahan Baku, Bahan Bakar dan Tenaga Kerja Terhadap Produksi Tempe Di Kota Semarang (Studi Kasus di Kelurahan Krobokan)", memberikan temuan bahwa terdapat hubungan yang signifikan antara variabel bahan baku terhadap produksi. Dari uraian tersebut maka dapat diperoleh hipotesis pertama, yaitu $\mathrm{H}_{1}=$ Perencanaan kebutuhan bahan baku berpengaruh signifikan terhadap kelancaran proses produksi.

Pengawasan Mutu Bahan Baku dengan Kelancaran Proses Produksi

Pengawasan mutu bahan baku (Assauri, 2008) merupakan usaha untuk mempertahankan mutu atau kualitas dari barang yang dihasilkan, agar sesuai dengan spesifikasi produk yang telah ditetapkan berdasarkan kebijaksanaan perusahaan. Pengawasan mutu semua produk yang dihasilkan harus diawasi sesuai dengan standar dan penyimpangan-penyimpangan yang terjadi harus dicatat serta dianalisis agara dapat digunakan untuk tindakantindakan perbaikan produksi pada masa yang akan datang, dari penelitian terdahulu (Robertus, 2012) dengan judul "Pengaruh Persediaan dan Kualitas Bahan Baku Terhadap Efisiensi Produksi Pada CV. Eka Jaya Jakarta", memberikan temuan bahwa terdapat hubungan yang signifikan antara variabel kualitas bahan baku terhadap efisiensi produksi. Dari uraian tersebut maka dapat diperoleh hipotesis kedua, yaitu $\mathrm{H}_{2}=$ Pengawasan mutu bahan baku berpengaruh signifikan terhadap kelancaran proses produksi.

\section{Perencanaan Kebutuhan Bahan Baku dan Pengawasan Mutu Bahan Baku dengan Kelancaran Proses Produksi}

Menurut Assauri (2009) faktorfaktor yang mempengaruhi kelancaran proses produksi adalah perencanaan dan pengendalian persediaan dan pengadaan bahan. Kelancaran kegiatan produksi dan operasi sangat ditentukan dan kelancaran tersedianya bahan yang dibutuhkan, bagi produksi dan operasi tersebut. Selain itu faktor penting yang mempengaruhi kelancaran proses produksi adalah pengendalian mutu, terjaminnya hasil atau keluaran dari proses produksi menentukan keberhasilan dan pengoperasian sistem produksi dan operasi, dari penelitian terdahulu (Robertus) menyimpulkan bahwa terdapat hubungan yang signifikan secara bersama-sama antar variabel persediaan dan variabel kualitas bahan baku terhadap efisiensi produksi. Dari uraian tersebut maka dapat 
diperoleh hipotesis ketiga, yaitu $\mathrm{H}_{3}=$ Perencanaan kebutuhan bahan dan pengawasan mutu bahan baku secara bersama-sama berpengaruh signifikan terhadap kelancaran proses produksi.

\section{METODE PENELITIAN}

Jenis data penelitian yaitu data sekunder dan sumber data diperoleh dari PT. Inkoasku, yaitu data laporan bulanan yang berisi laporan pembelian bahan baku, laporan produksi dan laporan material bahan baku yang rusak dari Januari 2013 - Desember 2015.

Metode pengambilan sampel dilakukan dengan cara purposive sampling, yaitu sampel diambil berdasarkan kriteria tertentu (Kuncoro, Mudrajad: 2004). Kriteria pengambilan sampelnya meliputi :

1. Laporan pembelian bahan baku periode Januari 2013 - Desember 2015 (36 bulan)

2. Laporan bulanan produksi periode 2013-2015

3. Laporan material bahan baku yang rusak periode 2013-2015
Jumlah sampel setiap bulan yang diambil tidak sama. Sepanjang data perusahaan memenuhi kriteria di atas, maka akan dijadikan sampel penelitian. Apabila tidak memenuhi kriteria di atas, maka data perusahaan tidak akan dimasukkan sebagai sampel penelitian. Adapun pengukuran variabel penelitian adalah sebagai berikut:

1. Kelancaran Proses Produksi

Kelancaran proses produksi (Y) akan diukur dengan satuan unit

2. Perencanaan Kebutuhan Bahan Baku Perencanaan kebutuhan bahan baku $\left(\mathrm{X}_{1}\right)$ akan diukur dengan Rupiah

3. Pengawasan Mutu Bahan Baku

Pengawasan mutu bahan baku $\left(\mathrm{X}_{2}\right)$ ini akan diukur dengan menggunakan alat ukur seperti mistar/penggaris dan bisa dilihat secara visual apperance. Data yang diperoleh dalam sebulan, merupakan akumulasi dari defect point yang telah dihitung per hari. Berikut kriteria defect yang ada pada PT. Inkoasku di Jakarta:

Tabel 3 Kriteria Defect Material

\begin{tabular}{|c|l|l|}
\hline $\begin{array}{c}\text { No. } \\
\text { Point }\end{array}$ & \multicolumn{1}{|c|}{ Jenis Defect } & \multicolumn{1}{c|}{ Standar } \\
\hline 1 & $\begin{array}{l}\text { Material Burry (hasil cutting } \\
\text { kasar) }\end{array}$ & Hasil cutting halus/tidak kasar \\
\hline 2 & $\begin{array}{l}\text { Material Scratch (cacat } \\
\text { gores/baret) }\end{array}$ & Tidak cacat gores/baret \\
\hline 3 & Material karat & Tidak ada karat \\
\hline 4 & $\begin{array}{l}\text { Tiger Mark (permukaan material } \\
\text { bopeng) }\end{array}$ & $\begin{array}{l}\text { Permukaan material halus/tidak } \\
\text { bopeng }\end{array}$ \\
\hline 5 & Lebar material tidak standar & Lebar material $=350 \mathrm{~mm} \pm 1 \mathrm{~mm}$ \\
\hline 6 & Panjang material tidak standar & $\begin{array}{l}\text { Panjang material }=1075 \mathrm{~mm} \pm 1 \\
\text { mm }\end{array}$ \\
\hline
\end{tabular}

\section{HASIL DAN PEMBAHASAN}

Dalam penelitan ini perencanaan kebutuhan bahan baku berpengaruh signifikan terhadap kelancaran proses produksi dengan nilai positif yaitu searah, sementara pengawasan mutu bahan baku berpengaruh signifikan terhadap kelancaran proses produksi dengan nilai yang negatif atau berlawanan arah, sedangkan 
perencanaan kebutuhan bahan baku dan pengawasan mutu bahan baku secara bersama-sama atau secara simultan $\begin{array}{lcc}\begin{array}{l}\text { berpengaruh } \\ \text { kelancaran }\end{array} & \begin{array}{l}\text { signifikan } \\ \text { proses }\end{array} & \begin{array}{r}\text { terhadap } \\ \text { produksi. }\end{array}\end{array}$

Tabel 4 Output Regresi

\begin{tabular}{|c|c|c|c|c|c|c|c|c|}
\hline \multicolumn{9}{|c|}{ Coefficients ${ }^{3}$} \\
\hline \multirow[b]{2}{*}{ Madel } & & \multicolumn{2}{|c|}{ Unstandardized Coefficients } & \multirow{2}{*}{$\begin{array}{c}\begin{array}{c}\text { Standardized } \\
\text { Coefficients }\end{array} \\
\text { Beta } \\
\end{array}$} & \multirow[b]{2}{*}{$t$} & \multirow[b]{2}{*}{ Sig. } & \multicolumn{2}{|c|}{ Collinearity Statistics } \\
\hline & & B & Std. Error & & & & Tolerance & VIF \\
\hline \multirow[t]{3}{*}{1} & (Constant) & -138.759 & 54.547 & & -2.544 & .016 & & \\
\hline & $\begin{array}{l}\text { Perencanaan Kebutuhan } \\
\text { Bahan Baku }\end{array}$ & .725 & .116 & .695 & 6.231 & .000 & .992 & 1.008 \\
\hline & $\begin{array}{l}\text { Pengawasan Mutu Bahan } \\
\text { Baku }\end{array}$ & -13.108 & 3.649 & -.400 & -3.593 & .001 & .992 & 1.008 \\
\hline
\end{tabular}

\section{SIMPULAN DAN SARAN}

Hasil pengujian hipotesis pertama ditemukan bukti empiris bahwa secara parsial, perencanaan kebutuhan bahan baku mempunyai pengaruh yang signifikan terhadap kelancaran proses produksi pada PT. Inkoasku di Jakarta. Arah pengaruh yang diberikan adalah pengaruh positif, yang berarti pengaruhnya searah.

Hasil pengujian hipotesis kedua ditemukan bukti empiris bahwa secara parsial pengawasan mutu bahan baku mempunyai pengaruh yang signifikan terhadap kelancaran proses produksi pada PT. Inkoasku di Jakarta. Arah pengaruh yang diberikan adalah pengaruh negatif, yang berarti pengaruhnya berlawanan arah.
Hasil pengujian hipotesis ketiga ditemukan bukti empiris bahwa secara simultan perencanaan kebutuhan bahan baku dan pengawasan mutu bahan baku secara bersama-sama berpengaruh signifikan terhadap kelancaran proses produksi pada PT. Inkoasku di Jakarta.

Penelitian selanjutnya diharapkan menambah jumlah tahun penelitian agar mendapatkan hasil penelitian yang lebih akurat

Penelitian selanjutnya diharapkan menambah jumlah variabel bebas dalam penelitian berikutnya seperti efisiensi waktu, layout dan variabel operasional lainnya. 


\section{DAFTAR PUSTAKA:}

Agung, I. G. N. ,2006, "Statistika Penerapan Model Retata-Sel Multivariat dan Model Ekonometri", Jakarta, Yayasan SAD Satria Bhakti.

Ahyari, Agus, 2001, Anggaran Perusahaan, Buku II, BPFE, Yogyakarta.

Assauri, Sofjan,2007, Manajemen Pemasaran Dasar-Dasar, Konsep dan Strategi, Edisi Pertama,

Assauri, Sofyan, 2004, Manajemen Pemasaran ; Dasar, Konsep dan Strategi. PT. Grafindo Persada. Jakarta

Barry Render and Jay Heizer, 2001, Prinsip-prinsip Manajemen Operasi, PT. Salemba Emban Patria, Jakarta.

Gujarati, Damodar, 2003, "Basic Econometrics", New York: McGraw-Hill Companies.

Hansen Don R, Maryanne M. Mowen, 2001 Akuntansi Manajemen, Edisi Kedua, terjemahan: A. Hermawan, Penerbit Erlangga, Jakarta.

Hasanah, 2008, "Pengendalian Persediaan Bahan Baku Terhadap Kelancaran Proses Produksi Kertas Wood Free (WF)".

Hery Prasetyo, Fibi Vebiastuti, 2000,"Manajemen Operasi", Media Presido, Yogyakarta.

Hilda, Miftahul, 2004, "Analisis Persediaan Bahan Baku (Kertas) Dalam Mendukung Kelancaran Proses Produksi Buku Pada PT. Balai Pustaka (Persero) Jakarta, Universitas 17 Agustus 1945 Jakarta.

Hill , Terry ,2000, The Essence of Operations Management, Andi, Yogyakarta.

Indriyo Gitosudarmo,2007, Pengantar Bisnis. Yogyakarta: BPFE.
Jogiyanto, Hartono, 2004, Pengenalan Komputer. Yogyakarta: C.V.ANDI OFFSET.

Kotler, Philip, 2002, Manajemen Pemasaran: Analisis, Perencanaan, implementasi dan Kontrol, Edisi Sebelas. Alih Bahasa, Hendra Teguh. Jakarta: Penerbit PT. Prenhallindo.

Kuncoro, Mudrajad, 2004,Ekonomi Pembangunan II. Jakarta: Pusat Penerbitan Universitas Terbuka.

Kuncoro,Mudrajad,2004,“Metode Kuantitatif:TeoridanAplikasiunt ukBisnisdanEkonomi", Yogyakarta, UPP AMP YKPN.

Miller, Rogeer LR, Meiners, 2000, Teori Ekonomi Intermediate, -Ed. 3.-, Raja

Mulyadi, 2007, Akuntansi Biaya. Yogyakarta : BPFE-UGM.

Mutiara,Ayu, 2010,"Analisis Pengaruh Bahan Baku, Bahan Bakar dan Tenaga Kerja Terhadap Produksi Tempe di Kota Semarang ( Studi Kasus di Kelurahan Krobokan)".Semarang :UniversitasDiponegoro

Nana Sudjana, 2005, Dasar-Dasar Proses Pembelajaran. Bandung: Sinar Baru Algosindo.

Rangkuti, Freddy, 2007, Riset Pemasaran. Gramedia Pustaka Utama, Jakarta.

Sedarmayanti, 2001 , "Sumber Daya Manusia dan Produktivitas Kerja", cetakan ketiga, Bandung: Penerbit CV. Mandar Maju.

Sitinjak,Robertus,2012,"Pengaruh PersediaandanKualitasBahan Baku TerhadapEfesiensiProduksiPada CV. Eka Jaya" Jakarta : UniversitasTujuhBelasAgustus

Sugianto, 2002,Metode Penelitian Bisnis. Penerbit CV. ALVA BETA. Bandung 
Sukanto Reksodiprojo, 2000, Indriyo Gito Sudono, "Manajemen Produksi “, BPFE, Yogyakarta.

T. Hani Handoko,2000, "Dasar- Dasar Manajemen Produksi dan Operasi, BPFE, Yogyakarta.

VincentGaspersz,2000,ManajemenProd uktivitas Total,
GramediaPustaka Jakarta.

W Gulo, 2005, Metodologi Penelitian. Cetakan keempat. Gramedia. Jakarta.

Yuningsih, Yanti, 2010, "Pengaruh Pengendalian Persediaan Bahan Baku Terhadap Kelancaran Proses Produksi”, Tasikmalaya, Universitas Siliwangi. 
Jurnal Manajemen Hasil Penelitian

Vol.13(2) : 85-191 Th. 2017

ISSN: 1907-0896 